\title{
Marc Ferro (1924-2021)
}

Le 21 avril 2021, Marc Ferro s'en est allé, laissant un grand vide dans les différents champs du savoir historique qu'il a traversés et marqués de son empreinte. Né la même année que Jacques Le Goff, il fut tout aussi ogre que son collègue des Annales : son œuvre immense frappe par la variété des domaines explorés comme des méthodes mises en œuvre.

Avant de devenir en France l'incarnation de l'historien public, ils'était imposécomme une référence de l'histoire de la révolution de 1917 et des régimes communistes, sujets auxquels il ne consacra pas moins d'une quinzaine d'ouvrages. À partir d'une analyse documentée, M. Ferro s'opposait tout autant à l'historiographie soviétique (et trotskiste), qui entendait montrer que la révolution avait suivi le modèle marxiste, qu'à ceux qui considéraient qu'ils'agissait d'un coup d'État planifiéet réussi grâce à la discipline du parti bolchevique.

Non sans relation avec ses recherches sur la Russie, M. Ferro a abordé les guerres mondiales dans cinq livres, sans jamais se départir d'un rapport aux sources primaires (ce fut un homme d'archives), osant aussi inventer des sources nouvelles (l'image en mouvement) et importer dans l'écriture de l'histoire des techniques cinématographiques (le flash-back) que l'on retrouve à l'œuvre dans ses films pour la télévision tels La Grande Guerre: 1914-1918 (1964), réalisé avec Solange Peter, et, surtout, les 630 émissions des Histoires parallèles (1989-2001), série créée à l'initiative de Louisette Neil, qui confrontaient les actualités cinématographiques à un demi-siècle de distance.

Passeur sans rival d'une rive à l'autre, celle de l'historiographie savante à l'histoire grand public, M. Ferro fut un historien jouissant d'une popularité exceptionnelle. Le film L'année 17 fut l'occasion d'un travail sur les archives russes qu'il utilisa également dans son opus suivant, Lénine par Lénine, réalisé par Pierre Samson. Il parvint à faire 
ressortir, par la force propre des images, les différences entre les manifestations russes de mars 1917, tantôt graves, tantôt allègres mais toujours spontanées, et celles de juin, déjà routinières, où perçait le désenchantement, tandis que celles d'octobre prenaient un tour violent et désespéré.

Les documentaires furent au cour du renouvellement historiographique impulsé par M. Ferro: il fut le grand défricheur, dès la fin des années 1960, des rapports entre cinéma et histoire. Ses travaux, d'abord publiés dans les Annales, intégraient les avancées de l'analyse sémiotique proposée par Christian Metz dans Langage et cinéma, dont il avait fait la recension en 1973. En outre, ses analyses filmiques visaient à mettre au jour, chaque fois, une zone d'histoire demeurée jusque-là cachée, insaisissable, non-visible. Non seulement l'œil de l'historien captait ce hors-champ, mais il réussissait dans le même temps à intégrer les anonymes dans le récit. Plutôt que de se laisser abuser par les arrêts sur images, il entendait retrouver leur mouvement et, au-delà, le cours heurté de l'histoire.

Loin de porter seulement sur l'aire européenne, son travail embrassait large, tant géographiquement que chronologiquement, car M. Ferro fut aussi un historien de la colonisation sur la longue durée. Si ce domaine d'enquête doit évidemment aux circonstances et aux engagements de sa vie, il y arriva par des chemins détournés. Il cultivait en effet l'art du contre-pied et du contretemps : en Algérie, il apprit la langue russe - sa mère était née dans l'importante communauté juive de la région de Jytomir, en Ukraine - à la surprise des collègues et amis qui s'attendaient à ce qu'il apprenne l'arabe. C'est cependant sur le terrain, en Algérie, qu'il s'intéressa non seulement au colonialisme et à l'Islam, mais aussi au communisme, notamment à sa politique au quotidien à l'égard des nationalités.

La vie et l'œuvre s'entrecroisent selon des temporalités éclatées, parfois discordantes, toujours inattendues. Qui attendait M. Ferro sur une biographie de Philippe Pétain (1987)? Lui, l'ancien jeune Franc-tireur et partisan, le maquisard du Vercors, dont la mère devait mourir en camp d'extermination, livra un ouvrage laissant admiratifs les spécialistes de la période. Il réussit le tour de force de combiner l'exploration et l'exploitation originale de sources jusqu'alors négligées et un point de vue distancié: Pétain, ou comment faire sujet quand même, malgré la blessure, et en bravant tous les interdits - y compris ceux de la mouvance historienne à laquelle M. Ferro appartenait, aux yeux de laquelle les grands hommes (fussent-ils des "salauds au sens sartrien») et l'histoire politique relevaient d'une histoire repoussoir, l' "histoire historisante».

G'est d'abord sous la houlette de Fernand Braudel que M. Ferro a assuré la direction des Annales à partir de 1962. Comme en témoignent déjà ses recherches sur la Révolution de 1917, il ne s'en tenait pas à une histoire événementielle, ni même aux "forces profondes », pour reprendre l'expression de son maître Pierre Renouvin, qui entendait par là les conditions démographiques, les forces économiques, les questions financières et les sentiments nationaux ou pacifistes. Avec franchise et piquant, $M$. Ferro est revenu sur sa relation aux Annales dans un entretien publié dans le numéro double spécial "Autoportrait d'une revue» précédant le présent volume. On y lit combien lui a importé, avec d'autres, d'ouvrir la revue à divers champs disciplinaires, par des articles, des débats ou des numéros spécialisés, surl'archéologie, l'anthropologie, la sociologie, la science politique, la linguistique, la psychanalyse, la sémiotique et aussi, bien entendu, le cinéma. Pendant les comités de rédaction, il intervenait vigoureusement, souvent pour défendre un article en difficulté 
dont il soutenait l'originalité. Son goût pour l'histoire politique puis pour l'écriture de biographies (Lénine, Pétain, Nicolas II, Staline, Roosevelt...) rappelle ainsi que, loin d'être un espace intellectuel homogène, la revue est traversée de sensibilités historiographiques et d'approches fort diverses.

Au-delà du chercheur, M. Ferro fut un extraordinaire professeur. Ses auditoires successifs ont décrit son art de captiver et de charmer, dans les séminaires à l'Institut du monde soviétique et de l'Europe centrale qu'il dirigeait, dans ceux sur le cinéma à l'EHESS qu'Ernest Labrousse, F. Braudel et Roland Barthes l'avaient incité à organiser en 1970, et même dans les amphithéâtres de l'École polytechnique. Sa force pédagogique ne tenait pas seulement à sa personne, mais aussi à sa méthode qui visait, par le recours au parallèle contrôlé, à aiguiser la vigilance démocratique. Il partageait cette passion de la transmission avec son épouse, enseignante en lycée, Yvonne Blondel, qui montait des pièces de théâtre avec ses élèves afin qu'ils investissent en personne et en corps les textes classiques. Cette intimité fut celle d'une communauté de cour et de combat qui débuta dans leur résistance commune. Il ne disparut que peu après qu'elle eut quitté ce monde, à ses côtés, centenaire.

Dans son désir de former des citoyens éclairés, $M$. Ferro s'est sans cesse élevé contre les figurations de l'histoire délibérément déformées par la propagande, celles que ses Histoires parallèles confrontaient pour les mettre en question. Plus largement, il s'est employé sans trêve à élargir l'horizon de ses auditeurs, spectateurs et lecteurs : en œuvrant au dialogue franco-allemand tout d'abord - favorisé notamment par la chaîne Arte à laquelle il a contribué-, alors qu'il conservait au plus vif la détresse irrémédiable de l'enfant dont la mère n'est jamais revenue des camps; en privilégiant un regard éloigné, loin des histoires nationales et européocentrées ensuite.

Dans sa préface aux Mélanges dédiés à M. Ferro, J. Le Goff ne saluait pas seulement l'historien et le citoyen, mais aussi "l'homme d'une générosité sans bornes ", "d'autant plus charmant au sens fort que sa gentillesse n'[était] ni faiblesse, ni manque de personnalité». Somme toute, M. Ferro fut un historien intensément vivant.

Les Annales 